\title{
Interventional Ischemic Stroke Treatment - A (R)evolution
}

\section{Die interventionelle Behandlung des ischämischen Schlaganfalls - eine (R)evolution}

Authors

Affiliations
B. Friedrich ${ }^{1}$, M. Gawlitza ${ }^{2}$, J. Fahnert ${ }^{1}$, U. Quäschling ${ }^{2}$, T. Kahn¹ , D. Lobsien², K.-T. Hoffmann ${ }^{2}$

Department of Diagnostic and Interventional Radiology, University Hospital Leipzig, Germany

2 Department of Neuroradiology, University Hospital Leipzig, Germany
Key words

- brain

- angiography

- ischemia/infarction

received 10.7.2015

accepted $\quad 24.8 .2015$

Bibliography

Dol http://dx.doi.org/

10.1055/s-0041-106899

Published online: 3.11.2015

Fortschr Röntgenstr 2016; 188:

259-267 @ Georg Thieme

Verlag KG Stuttgart . New York .

ISSN 1438-9029

\section{Correspondence}

\section{Dr. Benjamin Friedrich}

Department of Diagnostic and Interventional Radiology,

University Hospital Leipzig

Liebigstr. 20

04103 Leipzig

Germany

Tel.: ++ 49/341/9717447

Fax: $++49 / 341 / 9717480$

b.friedrich@medizin.uni-

leipzig.de

\section{Abstract \\ $\nabla$}

In recent years ischemic stroke caused by an intracranial vessel occlusion has become a treatable disease. Over decades intravenous thrombolysis by recombinant tissue plasminogen activator was the only accepted causal treatment of ischemic stroke supported by the results of randomized, controlled trials. However, there has been continuous development of endovascular treatment strategies over recent years. Today there are 5 prospective, randomized multicenter studies showing the highly significant superiority of endovascular, mechanical recanalization over intravenous thrombolysis in cases of acute occlusion of an intracranial vessel of the anterior circulation. In all those studies endovascular treatment resulted in a tremendous increase in functional independence together with a reduction of mortality without a significant increase in complications. This article reviews the developments resulting in the current data and gives an overview of the present studies focusing on endovascular stroke treatment.

Key Points:

- In the last 20 years ischemic stroke due to an main stem occlusion has become a potentially treatable disease.

- Several in 2015 published randomized Multicentener trials could prove the superiority of endovascular, mechanical recanalization over i.v. thrombolysis alone.

- Acute ischemic stroke due to a main stem occlusion should be treated with swift endovascular stent-retriever based recanalization in specialized neurovascular centers. Citation Format:

- Friedrich B, Gawlitza M, Fahnert J et al. Interventional Ischemic Stroke Treatment A (R)evolution. Fortschr Röntgenstr 2016; 188: 259-267

\section{Zusammenfassung \\ $\nabla$}

Der durch den Verschluss eines intrakraniellen Hauptstammes versursachte ischämische Schlaganfall hat sich in den letzten Jahren zu einer kausal behandelbaren Erkrankung entwickelt. Über Jahrzehnte war die intravenöse Lysetherapie mittels rekombinantem Tissue-Plasminogenaktivator einzige akzeptierte und durch die Ergebnisse randomisierter, kontrollierter Studien unterlegte ursächliche Behandlungsform des ischämischen Schlaganfalles. Jedoch hat in den letzten Jahren eine kontinuierliche Entwicklung endovaskulärer Behandlungskonzepte stattgefunden. Aktuell liegen 5 prospektive, randomisierte multizentrische Studien vor, die die hochsignifikante Überlegenheit der endovaskulären, mechanischen Rekanalisation gegenüber der intravenösen Lysetherapie bei akuten Verschlüssen der vorderen Zirkulation nachweisen. In all diesen Studien führte die endovaskuläre Behandlung zu einem deutlichen Anstieg des funktionell unabhängigen Lebens bei gleichzeitiger Reduktion der Mortalität ohne signifikanten Anstieg der Komplikationsraten. Dieser Artikel fasst die Entwicklungen, die zu diesen Ergebnissen geführt haben, zusammen und gibt eine Übersicht der aktuellen Studienlage zur Akuttherapie des ischämischen Schlaganfalls mit einem Fokus auf endovaskuläre Therapien.

\section{Introduction}

Ischemic stroke is an acute, potentially lifethreatening disease. It is caused by cerebral hypoperfusion primarily due to thromboembolic or local thrombotic vascular occlusions [1 -4]. If the occlusion and the resulting hypoperfusion are present for a long time, neuronal death occurs, resulting in irreversible damage to the affected brain areas [5]. Approximately 1.3 million people among the 
740 million inhabitants in Europe suffer from a stroke each year $[6,7]$. Since ischemic stroke causes high morbidity as a result of constant neurological deficits that result in possible lifelong dependence on nursing and physiotherapeutic care, strokes incur very high costs of approx. 26 billion Euros each year in Europe [7], To 1995, the diagnosis of a severe ischemic stroke almost always represented an individual health catastrophe that simply had to be accepted since no causal treatments were available. The only option was the best possible conservative treatment ("supportive care").

\section{Intravenous thrombolysis \\ $\nabla$}

The breakthrough in the treatment of ischemic stroke came in 1995 . The NINDS study led by the National Institute of Neurological Disorders and Stroke rt-PA Stroke Study Group was able to show in 624 patients that treatment with $0.9 \mathrm{mg} / \mathrm{kg}$ intravenously administered recombinant tissue plasminogen activator (rtPA) resulted in a good clinical outcome in $39 \%$ of patients ( $\mathrm{mRS}<3$, largely independent in daily activities) compared to only $26 \%$ in the placebo group [8]. This was the first indication of effective treatment of acute ischemic stroke. Candidates for IV thrombolysis were patients with symptom onset of less than 3 hours with no recent history of bleeding or operation. Contraindications were a severe coagulation defect or treatment with anticoagulants as well as arterial hypertension with a systolic RR $>185 \mathrm{mmHg}$ or diastolic RR $>110 \mathrm{mmHg}$. Intracranial bleeding - as an absolute contraindication for thrombolysis - as well as infarct demarcation had to be ruled out via non-contrast cranial computed tomography. As expected, the most frequent side effects of IV thrombolysis were bleeding complications, in particular intracranial bleeding. With $6.4 \%$ vs. $0.6 \%$, this occurred significantly more frequently after rtPA than after administration of the placebo. In the same year the "European Co- operative Acute Stroke Study" (ECASS) was published. In the target population, thrombolysis showed significant improvement of functional independence after 90 days. However, this result could not be confirmed in the intention-to-treat analysis. The rate of intracranial bleeding also increased significantly after rtPA as in the NINDS study [9]. Nonetheless, as a result of these two studies, the administration of rtPA for treating ischemic stroke was approved by the American Food and Drug Administration (FDA). In the following years, IV thrombolysis became established worldwide as a standard for the acute treatment of ischemic stroke. Despite the initially great optimism, it was seen relatively quickly that only approximately $3-5 \%$ of all stroke patients could undergo thrombolysis [10-12]. This was due to the list of contraindications as well as the narrow time window of 3 hours. For this reason, the studies at the start of the 2000 s concentrated on expanding the time window. A pooled evaluation of multiple studies yielded the first indications that treatment with rtPA could be effective beyond the time window of 3 hours [13]. In 2008, the third "European Cooperative Acute Stroke Study" (ECASS III study) was able to show the benefit of IV rtPA for the treatment of ischemic stroke even up to a time window of 4.5 hours after the onset of symptoms ( $\bullet$ Fig. 1) [14]. The treatment time window that was consequently expanded to 4.5 hours was confirmed in practical application by the treatment study "Safe Implementation of Thrombolysis in Stroke - International Stroke Thrombolysis Register" (SITS-ISTR) [15]. Despite the expanded inclusion criteria, patients with the most severe cases of stroke - caused by main stem occlusion at the circle of Willis - profited only comparatively little from intravenous thrombolysis $[16,17]$. The absolute risk reduction with respect to death or permanent disability was only between $13 \%$ (NINDS) and $7 \%$ (ECASS III) depending on the study $[8,14]$.

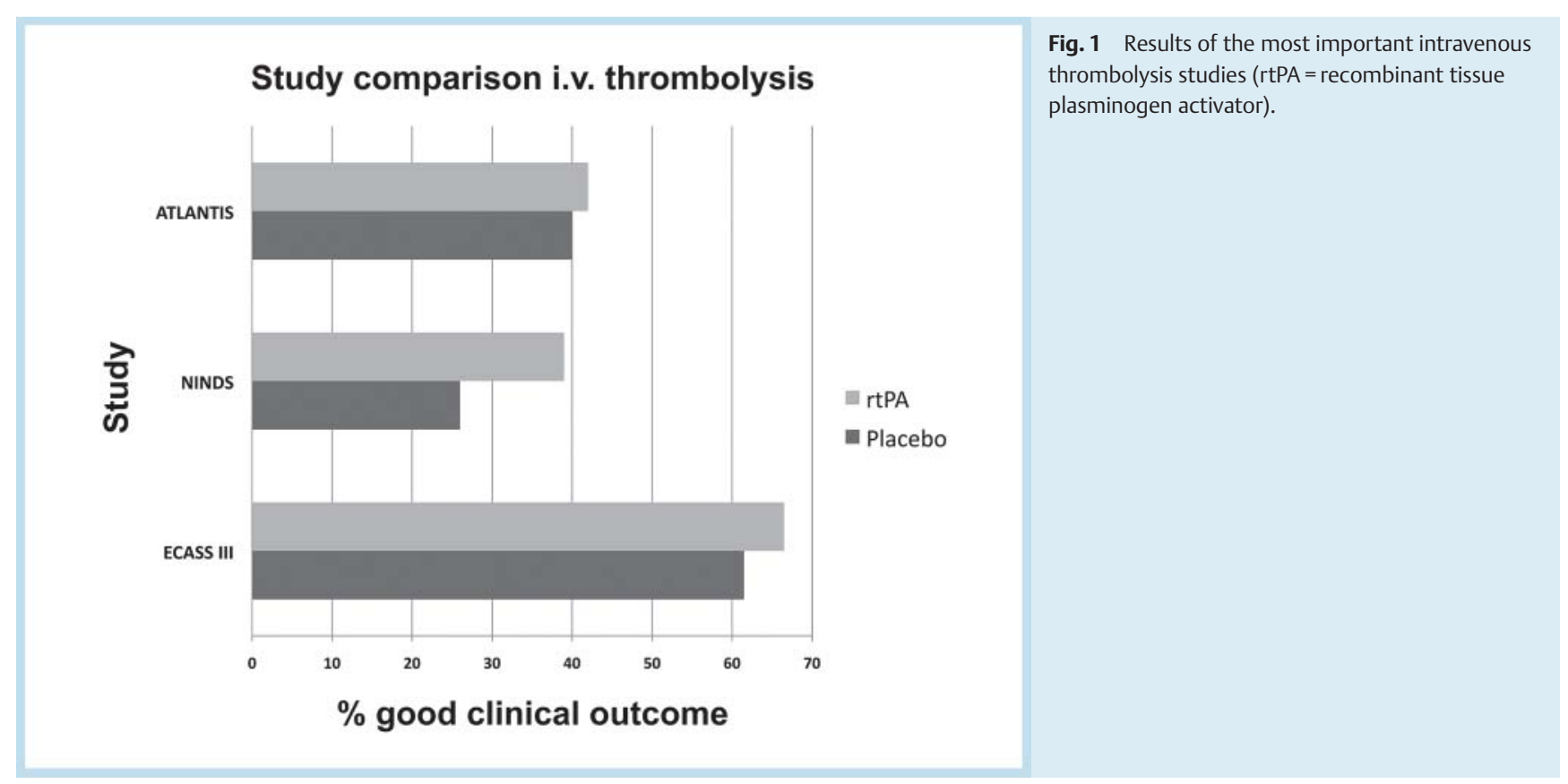




\section{The beginnings of interventional treatment}

Due to the often poor response of patients with intracranial main stem occlusion to IV thrombolysis, attempts have increasingly been made to treat these occlusions intraarterially with catheters. The local application of fibrinolytic substances via catheter immediately at or in the thrombus represented the start of interventional stroke treatment [18]. After several promising case reports and series were published, the PROACT II study was able to show in 1999 that the local application of urokinase achieved a substantial increase in the success rate of recanalization [19]. However, the clinical success lagged behind expectations and IV thrombolysis via rtPA continued to be the standard treatment. Nonetheless, the development of interventional stroke therapy continued, in the hope of further improving the clinical results as a result of improved techniques. An obvious idea was to retrieve the thrombus from the vessel instead of dissolving it in order to achieve immediate recanalization. The MERCI Retriever (Concentric Medical, USA) was the first device developed specifically for interventional stroke therapy. This corkscrew-like nitinol spiral was approved in 2004 by the FDA for the treatment of acute main stem occlusions within 8 hours of the onset of symptoms in the presence of contraindications for IV thrombolysis [20]. CE certification of the CATCH device (Balt Extrusion, France), a derivative of the LEO stent, in which the stent is suspended in a proximal concentric position from an insertion wire and is distally closed, was granted a year later. Both devices were based on the idea of initially passing the thrombus, placing the device distal to the thrombus, and then removing it via a retraction maneuver. This recanalization method was successful: The MERCI and MULTI MERCI studies published in 2005 and 2008 showed a significantly higher recanalization rate of the MERCI device compared to the PROACT II study so that use of the MERCI device in patients with contraindications to IV rtPA soon found broad acceptance [21, 22 ]. However, the recanalization rates of $45-60 \%$ in both studies were still not satisfactory. The embolism rate in other initially unaffected vascular territories in animal studies of up to $18 \%$ was also comparatively high [23]. These high embolism rates could not be confirmed in clinical use. In 2006, Penumbra (USA) presented a completely different approach: Use of an aspiration catheter with a dedicated aspiration pump together with a specially designed wire for fragmentation of the thrombus, called a separator [24]. The function principle was to suction the thrombus from a proximal position out of the vessel while inducing simultaneous fragmentation with the separator. This system was able to achieve recanalization rates of up to $80 \%$ in studies [25]. Thus, multiple competing mechanical recanalization methods for acute ischemic stroke for which an effectiveness in the presence of contraindications to IV rtPA was shown were available from the middle to the end of the first decade of the 2000 s. However, IV thrombolysis remained the global gold standard in first-line therapy.

\section{The era of the stent retriever}

\section{$\nabla$}

The breakthrough in interventional stroke therapy came in 2008 , more or less as a coincidence, as is often the case in medicine [26]. On the afternoon of March 3, 2008, a 67year-old patient suffering from a severe stroke caused by proximal occlusion of the middle cerebral artery was admitted to the Katharinenhospital in Stuttgart. 30 minutes after the start of IV thrombolysis, the patient's symptoms had not improved so that the indication for endovascular therapy was determined. After initial recanalization attempts with the above-mentioned approved devices remained unsuccessful, an interventional tool originally intended for a completely different indication, i.e. a stent, was implemented. The Solitaire Stent (ev3, USA) was originally approved in Europe in 2007 for stent-assisted coiling of intracranial aneurysms. In this case, i. e., the first off-label use of the stent in an acute stroke situation, the stent was released in the thrombus, but not detached and left in the vessel as originally intended by the manufacturer. After several minutes of allowing the stent to take effect by embedding in the thrombus, the stent was then drawn into the guide catheter under aspiration and removed. The result was immediate reopening of the occluded vessel by removing the thrombus. Despite the previous unsuccessful recanalization attempts, the intervention time remained less than an hour. After the end of the intervention, the patient awoke with only mild neurological symptoms that resolved fully within 3 months. This case launched a new era of interventional stroke therapy. The Solitaire Stent quickly became widely used as a thrombectomy device. Consequently, a specific variant of the Solitaire designed for thrombectomy (Solitaire FR) was developed and CEcertified in July 2009. In 2012 the experience of users was able to be proven in a first study: Use of the Solitaire Stent resulted in significantly higher recanalization rates than the previously used standard device, the MERCI Retriever, and in a significantly better clinical outcome [27]. Due the good success of the Solitaire as a stent retriever with high recanalization rates, multiple new devices with a similar function were developed in parallel, such as the TREVO (Concentric Medical), ReVive (Micrus, Codman and Shurtleff, USA) or pREset (phenox, Germany), to name a few of the most common ones. After the use of stent retrievers proved to be safe and technically comparatively simple and recanalization rates of up to $90 \%$ were reported in individual case series [28, 29], the question was increasingly posed as to whether this interventional treatment could be more than a last option in hopeless cases and whether it could be an alternative to the current standard of firstline therapy of ischemic stroke, i.e., thrombolysis via IV rtPA.

\section{The "backlash" in 2013 \\ $\nabla$}

At the beginning of February 2013, three randomized multicenter studies for clarifying the question of whether interventional stroke therapy is superior to IV thrombolysis appeared in an issue of the New England Journal of Medicine, i. e., "Interventional Management of Stroke Trial" (IMS 
III), "Mechanical Retrieval and Recanalization of Stroke Clots Using Embolectomy" (MR RESCUE) and "Intra-Arterial Versus Systemic Thrombolysis for Acute Ischemic Stroke" (SYNTHESIS) [30 - 32]. All three studies independently came to the conclusion that the clinical results of intraarterial stroke therapy are only equivalent to IV thrombolysis and are not superior. These results contradicted in many respects the experience particularly of interventional neuroradiolgists and neurologists treating strokes on a daily basis, thus igniting an extremely critical discussion. Why were the study results negative or the studies not capable of proving the superiority of intraarterial therapy? Major weaknesses in the planning, implementation, and interpretability of these three studies were identified as causes. IMS III was an international multicenter study with the goal of proving the superiority of intraarterial stroke therapy compared to standard therapy via IV rtPA alone. In total, 656 patients were included before the study was prematurely ended. Due to the very long recruiting period, every device approved for the indication of intraarterial stroke therapy was also approved for use in the study. However, the majority of patients randomized in the interventional arm were treated exclusively with the local application of rtPA $(\mathrm{N}=142)$ followed by older devices like the MERCI Retriever $(\mathrm{N}=95)$. Superior, modern stent retrievers were only used for an extremely small number of patients $(\mathrm{N}=5,0.8 \%)[30,33]$. This resulted in significantly worse recanalization rates of less than $50 \%$ compared to the stent retriever studies. A further significant weakness was the selection of patients. The pragmatic approach of randomizing patients exclusively according to their clinical presentation and after exclusion of bleeding via non-contrast CT was selected. This resulted in almost one fourth of patients ( $24 \%$ ) randomized into the intraarterial arm not receiving intraarterial therapy since no treatable vascular occlusion could be detected on angiography. The SYNTHESIS study, an Italian multicenter study, also missed the defined target of proving the superiority of intraarterial therapy compared to IV therapy in relation to the clinical outcome of achieving the greatest possible independence in the daily routine after 90 days. In total, 362 patients were included in this study and randomized into intraarterial versus IV therapy. Significantly outdated techniques were also used in this study (fragmentation with a microwire, local thrombolysis, use of a stent retriever only in $5 \%$ ) in 2013. Recanalization results were not reported [32]. Finally the MR RESCUE study examined whether intraarterial therapy is superior to standard therapy if multimodal MRI imaging is used for selection. In total, 127 patients were included, and intraarterial treatment was performed either via MERCI retriever or Penumbra aspiration system. Successful recanalization could be achieved in $67 \%$ of cases and again intraarterial therapy was shown not to be superior to IV therapy in the clinical 90-day result. In addition to the already outdated recanalization methods used in the MR RESCUE study, time management is another possible obstacle to the success of the study. The average time from the onset of symptoms to groin puncture and the start of the intervention was more than 6 hours (381 +/- 74 minutes) [31].
These three studies published simultaneously in one of the most well-respected medical journals initially represented a harsh backlash for endovascular stroke therapy. Due to the apparent study design flaws that became evident during implementation, new prospective randomized multicenter studies were planned partially in parallel regarding the question of whether intraarterial therapy using modern (current) recanalization techniques and devices is indeed superior to IV therapy.

\section{The breakthrough for interventional stroke therapy $\nabla$}

In October 2014, the results of the first new recanalization study, "The multicenter collaboration for endovascular treatment of acute ischemic stroke in the Netherlands" (MR CLEAN), were presented at the 9th World Stroke Conference in Istanbul. This Dutch multicenter study randomized 500 patients with a verified occlusion of a main stem of the anterior circulation and symptom onset of less than 6 hours either into standard therapy or additional mechanical recanalization ( $\bullet$ Table 1,2 ) [34]. In principle, there were no specifications regarding recanalization devices. Physicians were able to make decisions based on the situation and their own experience. In $81.5 \%$ of cases mechanical recanalization via modern stent retriever was selected ( $\bullet$ Table 3 ). Successful recanalization, defined as a thrombolysis in cerebral infarction (TICI) value of $2 \mathrm{~b}$ or 3 , was achieved in $58.7 \%$ of cases. This resulted in a functional independence (modified Rankin Scale $\mathrm{mRS}<=2$ ) of $32.6 \%$ of patients after 90 days ( $\bullet$ Table 4 ). Patients treated only with IV thrombolysis reached this primary end point in only $19.1 \%$ of cases ( $\bullet$ Fig. 2 ). These results were thus able to reflect for the first time the already empirically proven reality: The use of mechanical recanalization in patients with a proven main stem occlusion was superior to IV thrombolysis alone within a time window of 6 hours with high significance and almost doubled the probability of the patient being able to live an independent life 90 days after a stroke. The two groups had a 90-day mortality rate of $22 \%$ and $21 \%$, respectively. The other side effect profile did not show a significant difference between the two treatment groups particularly with respect to bleeding complications.

After this study showed the superiority of mechanical recanalization for the first time, 4 parallel studies (ESCAPE, EXTEND IA, SWIFT PRIME and REVASCAT) with largely the same goal were terminated for ethical reasons and were analyzed. The results were initially presented at conferences and were then also published in the New England Journal of Medicine in the first half of 2015. All studies differed with respect to design, but largely came to the same result:

- In addition to detected vascular occlusion, ESCAPE selected patients based on the degree of collateralization using multiphasic CTA and also had the biggest time window of 12 hours. Recanalization TICI 2b/3 was achieved in $72.4 \%$ of cases and $53 \%$ of patients were functionally independent 90 days after recanalization in contrast to $29.3 \%$ after IV thrombolysis. The mortality rate was able to be cut in half by endovascular recanalization [35]. 
Table 1 Study inclusion criteria.

\begin{tabular}{|c|c|c|c|c|c|}
\hline & MR CLEAN & ESCAPE & EXTEND-IA & SWIFT-PRIME & REVASCAT \\
\hline time window & $6 \mathrm{~h}$ & $12 \mathrm{~h}$ & $\begin{array}{l}6 \mathrm{~h} \text { (intervention } \\
\text { ended after } 8 \mathrm{~h} \text { ) }\end{array}$ & $6 \mathrm{~h}$ & $8 \mathrm{~h}$ \\
\hline NIHSS & $>2$ & $>5$ & no data & $>=8$ and $<30$ & $>=6$ \\
\hline imaging & $\begin{array}{l}\mathrm{NCCT}+\mathrm{CTA} / \mathrm{MRI}+ \\
\mathrm{MRA} / \mathrm{DSA}\end{array}$ & $\begin{array}{l}\text { NCCT + CTA } \\
\text { (multiphasic) }\end{array}$ & $\mathrm{NCCT}+\mathrm{CTA}+\mathrm{CTP}$ & $\begin{array}{l}\text { NCCT + CTA / MRI + } \\
\text { MRA (perfusion } \\
\text { in the first } 71 \\
\text { patients) }\end{array}$ & $\begin{array}{l}\text { NCCT + CTA / MRI + } \\
\text { MRA (perfusion } \\
\text { optional) }\end{array}$ \\
\hline occlusion & $\begin{array}{l}\text { carotid-T, M1 - } 2 \text {, } \\
\mathrm{A} 1 ; \mathrm{ACl} \text { stent+PTA } \\
\text { no exclusion }\end{array}$ & $\begin{array}{l}\text { carotid-T, M1 or M1 } \\
\text { equivalent ( } 2 \text { or more } \\
\text { M2 branches); } \mathrm{ACl} \text { stent } \\
\text { +PTA no exclusion }\end{array}$ & $\begin{array}{l}\text { carotid-T, M1-2; } \\
\text { ACl stent+PTA } \\
\text { no exclusion }\end{array}$ & $\begin{array}{l}\text { carotid-T, M1; } \\
\text { only PTA of } \\
\text { ACl allowed }\end{array}$ & $\begin{array}{l}\text { carotid-T, M1; } \\
\text { ACl stent+PTA } \\
\text { no exclusion }\end{array}$ \\
\hline functional imaging & - & $\begin{array}{l}\text { moderate to good } \\
\text { collateralization }\end{array}$ & $\begin{array}{l}\text { penumbra: tmax > 6s; } \\
\text { infarct core: }<70 \mathrm{ml}+ \\
\mathrm{rCBF}<30 \% \text {; } \\
\text { mismatch: }>1.2+ \\
>10 \mathrm{ml}\end{array}$ & $\begin{array}{l}\text { for the first } 71 \\
\text { patients: Mismatch } \\
>1.8+>15 \mathrm{ml}+\text { in- } \\
\text { farct core }<50 \mathrm{ml}\end{array}$ & - \\
\hline
\end{tabular}

NIHSS = National Institute Of Health Stroke Scale; NCCT = non-contrast cranial CT; CTA = CT angiography; 1 1 = 1st segment of the anterior cerebral artery; $\mathrm{M} 1, \mathrm{M} 2=1 \mathrm{st}$ or $2 \mathrm{nd}$ segment of the middle cerebral artery; $\mathrm{ACl}=$ internal carotid artery; $\mathrm{PTA}=$ percutaneous transluminal angioplasty; $\mathrm{rCBF}=$ relative cerebral blood flow, $\mathrm{Tmax}=$ time to bolus maximum .

\begin{tabular}{|llllll|}
\hline & MR CLEAN & ESCAPE & EXTEND-IA & SWIFT-PRIME & REVASCAT \\
\hline carotid-T & $27 \%$ & $27 \%$ & $31 \%$ & $18 \%$ & $26 \%$ \\
\hline M1 & $64 \%$ & $70 \%$ & $54 \%$ & $72 \%$ & $65 \%$ \\
\hline M2 & $8 \%$ & $3 \%$ & $15 \%$ & $10 \%$ & $9 \%$ \\
\hline A1/A2 & $1 \%$ & - & - & - & - \\
\hline $\begin{array}{l}\text { cervical ACl } \\
\text { (stenosis/occlusion) }\end{array}$ & $29 \%$ & $12.7 \%$ & $8.6 \%$ & $4 \%$ (only PTA) & $14.5 \%$ \\
\hline
\end{tabular}

Table 2 Location of occlusion in study patients.

The numbers form averages for the particular study collectives. Abbreviations: M1, M2 =1st or 2nd segment of the middle cerebral artery; $\mathrm{A} 1, \mathrm{~A} 2=1$ st or 2 nd segment of the anterior cerebral artery; PTA = percutaneous transluminal angioplasty.

Table 3 Description of the interventions in the studies.

\begin{tabular}{|c|c|c|c|c|c|}
\hline & MR CLEAN & ESCAPE & EXTEND-IA & SWIFT-PRIME & REVASCAT \\
\hline IV rtPA & $\begin{array}{l}\text { not a mandatory } \\
\text { inclusion criterion }\end{array}$ & $\begin{array}{l}\text { not a mandatory } \\
\text { inclusion criterion }\end{array}$ & yes & yes & $\begin{array}{l}\text { yes (IA treatment only } \\
\text { if no improvement } \\
\text { after } 30 \text { minutes) }\end{array}$ \\
\hline device & all (81.5 \% stent retriever) & all ( 86.1 \% stent retriever) & solitaire & solitaire & solitaire \\
\hline anesthesia & $37.8 \%$ IN & $9.1 \%$ IN & $36 \%$ IN & $37 \%$ IN & $6.7 \% \mathrm{IN}$ \\
\hline \multicolumn{6}{|l|}{ times } \\
\hline $\begin{array}{l}\text { onset of symptoms - } \\
\text { rtPA [min] }\end{array}$ & 86 & 115 & 145 & 117 & 110 \\
\hline $\begin{array}{l}\text { onset of symptoms - } \\
\text { groin puncture [min] }\end{array}$ & 260 & 185 & 210 & 224 & 269 \\
\hline $\begin{array}{l}\text { imaging - groin } \\
\text { puncture [min] }\end{array}$ & n.a. & 51 & 93 & 57 & 77 \\
\hline $\begin{array}{l}\text { onset of symptoms - } \\
\text { reperfusion [min] }\end{array}$ & n.a. & 241 & 248 & 252 & 355 \\
\hline
\end{tabular}

rtPA = recombinant tissue plasminogen activator; IN = endotracheal anesthesia; $I A=$ intraarterial.

- EXTEND IA was characterized by the most complex imaging selection method: In addition to a detected vascular occlusion, CT perfusion imaging had to show a small infarct core $(<70 \mathrm{ml})$ and a large salvageable penumbra ( $>1.2$ times the infarct core). The time window was 6 hours. Moreover, the Solitaire Stent Retriever was the only approved device. Successful recanalization was achieved in this study in $86 \%$ of cases, resulting in a $90-$ day $\mathrm{mRS}<=2$ in $71 \%$ of cases compared to $40 \%$ after IV thrombolysis. The mortality rate was again cut in half by intraarterial therapy [36].

- In the first half of the study, SWIFT PRIME included patients with a detected vascular occlusion and a salvageable penumbra detected via perfusion imaging within 6 hours. In the second half of the study, perfusion imaging was no longer a mandatory inclusion criterion. Patients were treated with the Solitaire. Cervical carotid occlusions requiring stenting were an exclusion criterion. 


\begin{tabular}{|c|c|c|c|c|c|}
\hline & MR CLEAN & ESCAPE & EXTEND-IA & SWIFT-PRIME & REVASCAT \\
\hline number of patients & 500 & 316 & 70 & 196 & 206 \\
\hline $\begin{array}{l}\text { successful recanalization } \\
(\mathrm{TICI} 2 \mathrm{~b} / 3)\end{array}$ & $58.7 \%$ & $72.4 \%$ & $86 \%$ & $88 \%$ & $65.7 \%$ \\
\hline \multicolumn{6}{|l|}{ outcome $90 \mathrm{~d} \mathrm{mRS}<=2$} \\
\hline rtPA & $19.1 \%$ & $29.3 \%$ & $40 \%$ & $35 \%$ & $28.2 \%$ \\
\hline intervention & $32.6 \%$ & $53 \%$ & $71 \%$ & $60 \%$ & $43.7 \%$ \\
\hline \multicolumn{6}{|l|}{ mortality } \\
\hline rtPA & $22 \%$ & $19 \%$ & $20 \%$ & $12 \%$ & $15.5 \%$ \\
\hline intervention & $21 \%$ & $10 \%$ & $9 \%$ & $9 \%$ & $18.4 \%$ \\
\hline \multicolumn{6}{|l|}{$\mathrm{SICH}$} \\
\hline rtPA & n.a. & $2.7 \%$ & $6 \%$ & $3 \%$ & $1.9 \%$ \\
\hline intervention & n.a. & $3.6 \%$ & $0 \%$ & $0 \%$ & $1.9 \%$ \\
\hline
\end{tabular}

Table 4 Results of the studies.

Abbreviations: $\mathrm{TICl}=$ Thrombolysis in Cerebral Infarction Score; mRS = modified Rankin Scale; rtPA = recombinant tissue plasminogen activator; $\mathrm{sICH}=$ symptomatic intracranial hemorrhage.

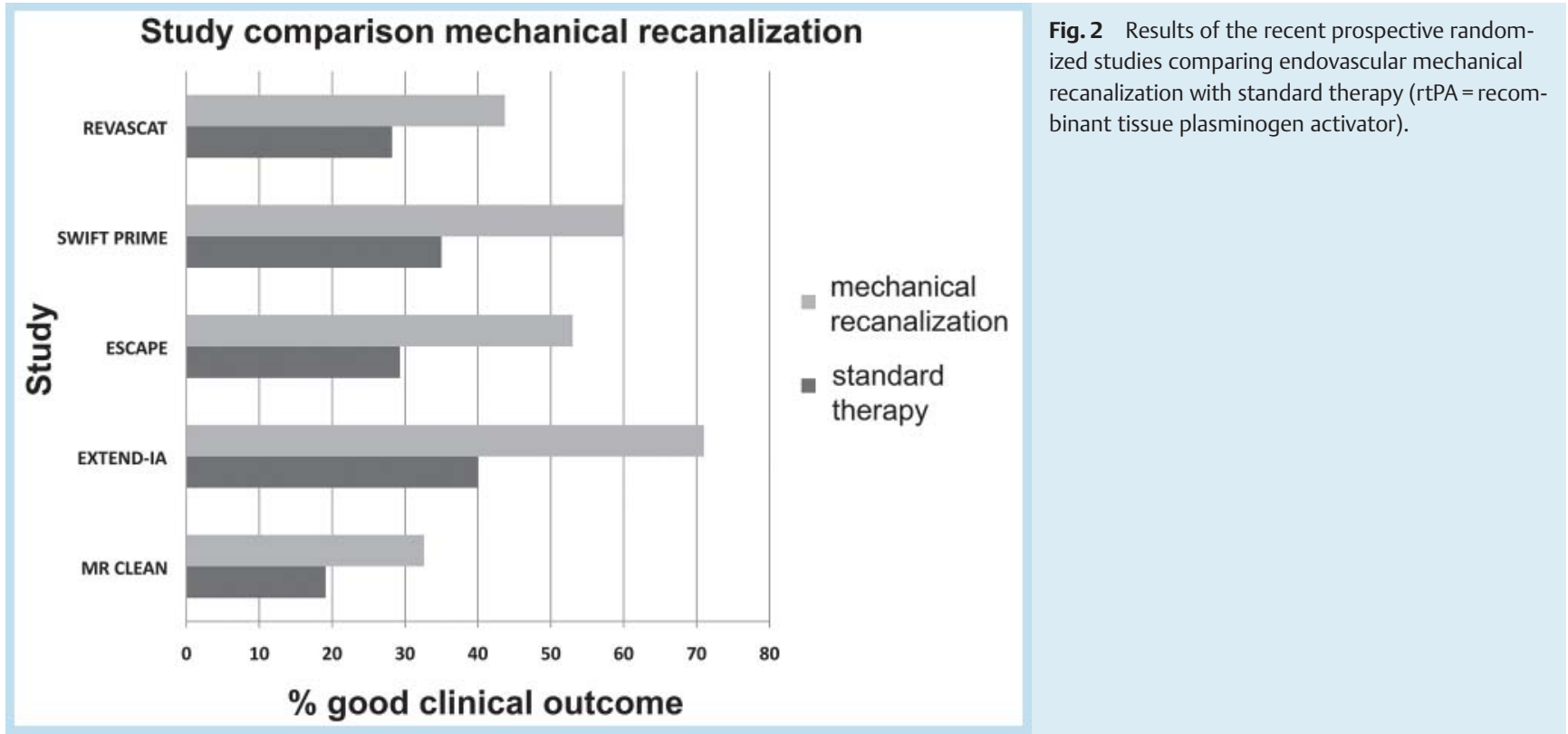

$88 \%$ of patients were able to be successfully recanalized. $60 \%$ of patients were functionally independent after i.a. therapy compared to $35 \%$ after IV thrombolysis [37].

- REVASCAT included patients within 8 hours of the onset of symptoms. To be randomized, the patients were not allowed to have experienced symptom improvement 30 minutes after the start of IV thrombolysis. Recanalization was also only performed with the Solitaire and was successful in $65.7 \%$ of cases. $43.7 \%$ of patients showed a $90-$ day $m R S<=2-$ a result that was achieved in only $28.2 \%$ of patients after IV thrombolysis [38].

The significantly higher rates of patients with a functionally independent life after 90 days in SWIFT PRIME and EXTEND-IA compared to MR CLEAN can probably be explained by the very different rate of pathologies in the region of the cervical carotid artery and the carotid-T ( $\bullet$ Table 2 ). Patient selection was also significantly aligned with multimodal imaging particularly in EXTEND-IA in order to select patients who would most probably profit from endovascular recanalization. Based on this fact, results in the clinical reality will tend to correspond more with the results of the MR CLEAN study.
Thus, 5 studies of the highest evidence class have been available since April 2015 that were able to independently prove the superiority of intraarterial recanalization via stent retriever compared to IV thrombolysis in the case of acute occlusion of the anterior cerebral circulation and this according to the results of the currently available subgroup analyses with a time window of up to at least 6 hours (see the following section "The future") and independently of patient age (patients over 80 years or 65 years, depending on the inclusion criteria, profit as much as younger patients [34-38]).

Due to the overwhelming evidence for recanalization with a number-needed-to-treat for a functionally independent life of 3-5 [39], a consensus statement of multiple European and American professional societies was quickly published with the clear recommendation to implement mechanical recanalization as the standard treatment method ( $\bullet$ Fig.3) $[40,41]$. 


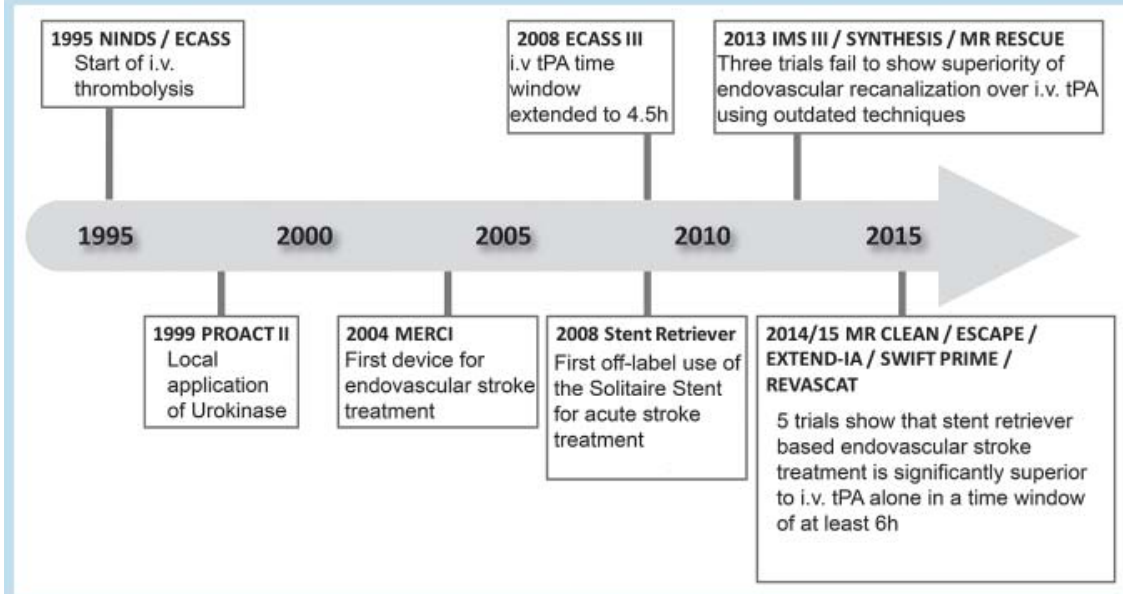

Fig. 3 Chronological sequence of the most important studies and technical developments of interventional stroke treatment.

\section{The future}

\section{$\nabla$}

A joint guideline of multiple European professional societies (ESO, ESMINT and ESNR) regarding interventional stroke therapy which will include the results of two additional studies (THRACE, THERAPY) only presented at conferences to date is expected to still be published this year.

Despite or partly because of the impressive data, there are still some questions regarding clinical practice and future studies:

1. How will patients be distributed in the future? Given the estimated 10000 patients who are considered each year for recanalization in Germany, it may not be necessary to increase the number of neuroradiological-neurovascular centers. However, quick diagnosis and immediate transfer from primary care to neurovascular centers must be significantly improved and the resources in these centers for interventional stroke therapy must be adapted to an increasing number of cases.

2. Is "time window" still current as a term and selection criterion? A time window has always been a surrogate parameter for the probability of still vital brain tissue. Today there are imaging methods with which the vitality of brain tissue can be visualized. In the ESCAPE study, for example, $15.5 \%$ of patients were treated later than 6 hours after the onset of symptoms. It seems possible to identify patients who would profit after long intervals as much as patients with a shorter symptom duration on the basis of results of selection criteria based on imaging, e.g., collateralization analysis [35].

3. What are the treatment options for patients suffering from a "wake-up" stroke (with an unknown onset of symptoms)? The ability to treat this patient collective with interventional procedures must be examined in future studies with multimodal imaging.

4. Which types of occlusion profit from intraarterial treatment? According to the currently available studies, carotid-T and M1 occlusions undoubtedly profit from recanalization. However, the outcome of the use of thrombectomy in more distal occlusions has not yet be definitively determined. Nonetheless, individual case series have been able to show excellent results in some more distal occlusions without a significant increase in complications $[42,43]$. However, there are no random- ized studies with a comparison group, and this is crucial since distal occlusions also benefit from intravenous thrombolysis [44]. More precise methods for determining the location of the occlusion (e. g. the distance to the thrombus [45], etc.) may need to be used here. The posterior circulation must also be examined in greater detail with regard to the use of modern stent retrievers. A study examining this question has already been initiated [46].

5. General anesthesia or conscious sedation? Mechanical, endovascular recanalization can in principle be performed under general anesthesia or under conscious sedation. There are major differences regarding which anesthesia method is used between the different centers. Shorter procedure times, fewer roadmaps, less pain for the patient, and a lower risk of aspiration are specified as advantages for general anesthesia due to the stillness of the patient. The lower rate of respiratory complications and the lack of a potentially fatal drop in blood pressure during general anesthesia are advantages of conscious sedation. The rate of patients treated under general anesthesia varies greatly in the above studies ( Table 3). A study to clarify this question has already been launched [47].

6. Who should perform mechanical recanalization? All mentioned endovascular studies were performed exclusively by neuroradiologists with interventional experience. The procedure should be performed exclusively by colleagues who have substantial experience with the initial diagnosis of a stroke, with procedure implementation, and with the treatment of any resulting periprocedural complications. Thus, mechanical recanalization of ischemic stroke should continue to be reserved for (neuro-) radiologists with experience in interventional neuroradiology in neurovascular centers in the future. This is also recommended in the already mentioned consensus statement of different professional societies [40]. 


\section{Summary}

$\nabla$

Interventional therapy of ischemic stroke due to an intracranial main stem occlusion of the anterior circulation via stent retriever-based recanalization within 6 hours of the onset of symptoms is significantly superior to thrombolytic therapy via IV rtPA alone and increases the probability of patients leading a functionally independent life with a simultaneous reduction of mortality. It should therefore be viewed as the standard therapy to be provided nationwide in neuroradiology departments.

\section{References}

1 Adams HP, Bendixen BH, Kappelle LJ et al. Classification of subtype of acute ischemic stroke. Definitions for use in a multicenter clinical trial. TOAST. Trial of Org 10172 in Acute Stroke Treatment. Stroke 1993; 24 : $35-41$

2 Jansen $O$, von Kummer R, Forsting $M$ et al. Thrombolytic therapy in acute occlusion of the intracranial internal carotid artery bifurcation. American Journal of Neuroradiology 1995; 16: 1977-1986

3 Brandt T, von Kummer R, Müller-Küppers $M$ et al. Thrombolytic therapy of acute basilar artery occlusion. Variables affecting recanalization and outcome. Stroke 1996; 27: 875-881

4 Hacke W, Schwab S, Horn $M$ et al. "Malignant" middle cerebral artery territory infarction: clinical course and prognostic signs. Arch Neurol 1996; 53: 309-315

5 Meretoja A, Keshtkaran M, Saver JL et al. Stroke thrombolysis: save a minute, save a day. Stroke 2014; 45: 1053-1058

6 Tatlisumak T. Implication of the Recent Positive Endovascular Intervention Trials for Organizing Acute Stroke Care: European Perspective. Stroke 2015; 46: 1468-1473

7 Gustavsson A, Svensson M, Jacobi F et al. Cost of disorders of the brain in Europe 2010. Eur Neuropsychopharmacol 2011; 21: 718-779

8 The National Institute of Neurological Disorders and Stroke rt-PA Stroke Study Group. Tissue plasminogen activator for acute ischemic stroke. N Engl J Med 1995; 333: 1581 - 1587

9 Hacke $W$, Kaste $M$, Fieschi $C$ et al. Intravenous thrombolysis with recombinant tissue plasminogen activator for acute hemispheric stroke. The European Cooperative Acute Stroke Study (ECASS). Jama 1995; 274: $1017-1025$

10 Moradiya Y, Crystal H, Valsamis $H$ et al. Thrombolytic utilization for ischemic stroke in US hospitals with neurology residency program. Neurology 2013; 81: 1986-1995

11 Kleindorfer $D$, de los Rios La Rosa F, Khatri P et al. Temporal trends in acute stroke management. Stroke 2013; 44: S129-S131

12 Nasr DM, Brinjikji W, Cloft HJ et al. Utilization of intravenous thrombolysis is increasing in the United States. Int J Stroke 2013; 8: 681-688

13 Hacke W, Donnan G, Fieschi C et al. Association of outcome with early stroke treatment: pooled analysis of ATLANTIS, ECASS, and NINDS rtPA stroke trials. Lancet 2004; 363: $768-774$

14 Hacke W, Kaste M, Bluhmki E et al. Thrombolysis with alteplase 3 to 4.5 hours after acute ischemic stroke. N Engl J Med 2008; 359: 1317-1329

15 Wahlgren N, Ahmed N, Dávalos A et al. Thrombolysis with alteplase 3$4.5 \mathrm{~h}$ after acute ischaemic stroke (SITS-ISTR): an observational study. Lancet 2008; 372: 1303-1309

16 Alexandrov AV, Molina CA, Grotta JC et al. Ultrasound-enhanced systemic thrombolysis for acute ischemic stroke. N Engl J Med 2004; 351: $2170-2178$

17 Ding $D$. Intravenous versus intra-arterial thrombolysis for anterior circulation stroke secondary to large vessel occlusion. J Stroke Cerebrovasc Dis 2015; 24: 718-719

18 Zeumer H, Hacke W, Kolmann HL et al. Local fibrinolysis in basilar artery thrombosis. Dtsch Med Wochenschr 1982; 107: 728-731

19 Furlan A, Higashida R, Wechsler L et al. Intra-arterial prourokinase for acute ischemic stroke. The PROACT II study: a randomized controlled trial. Prolyse in Acute Cerebral Thromboembolism. Jama 1999; 282: 2003-2011

20 Gobin YP, Starkman S, Duckwiler GR et al. MERCI 1: a phase 1 study of Mechanical Embolus Removal in Cerebral Ischemia. Stroke 2004; 35 : $2848-2854$
21 Smith WS, Sung G, Starkman S et al. Safety and efficacy of mechanical embolectomy in acute ischemic stroke: results of the MERCI trial. Stroke 2005; 36: 1432 - 1438

22 Smith WS, Sung G, Saver J et al. Mechanical thrombectomy for acute ischemic stroke: final results of the Multi MERCI trial. Stroke 2008; 39: $1205-1212$

23 Brekenfeld C, Schroth G, El-Koussy M et al. Mechanical thromboembolectomy for acute ischemic stroke: comparison of the catch thrombectomy device and the Merci Retriever in vivo. Stroke 2008; 39: 1213 1219

24 Bose A, Henkes H, Alfke K et al. The Penumbra System: a mechanical device for the treatment of acute stroke due to thromboembolism. Am J Neuroradiol 2008; 29: 1409-1413

25 Penumbra Pivotal Stroke Trial Investigators. The penumbra pivotal stroke trial: safety and effectiveness of a new generation of mechanical devices for clot removal in intracranial large vessel occlusive disease. Stroke 2009; 40: 2761 - 2768

26 Pérez MA, Miloslavski E, Fischer $S$ et al. Intracranial thrombectomy using the Solitaire stent: a historical vignette. J Neurointerv Surg 2012; 4: e32-e32

27 Saver JL, Jahan R, Levy EI et al. Solitaire flow restoration device versus the Merci Retriever in patients with acute ischaemic stroke (SWIFT): a randomised, parallel-group, non-inferiority trial. Lancet 2012; 380: $1241-1249$

28 Dorn F, Stehle S, Lockau H et al. Endovascular treatment of acute intracerebral artery occlusions with the solitaire stent: single-centre experience with 108 recanalization procedures. Cerebrovasc Dis 2012; 34: $70-77$

29 Cohen JE, Gomori JM, Leker RR et al. Preliminary experience with the use of self-expanding stent as a thrombectomy device in ischemic stroke. Neurol Res 2011; 33: 214-219

30 Broderick JP, Palesch YY, Demchuk AM et al. Endovascular therapy after intravenous t-PA versus t-PA alone for stroke. N Engl J Med 2013; 368: 893-903

31 Kidwell CS, Jahan R, Gornbein J et al. A trial of imaging selection and endovascular treatment for ischemic stroke. N Engl J Med 2013; 368: 914-923

32 Ciccone A, Valvassori L, Nichelatti $M$ et al. Endovascular treatment for acute ischemic stroke. N Engl J Med 2013; 368: 904 -913

33 von Kummer R, Gerber J. IMS-3, synthesis, and MR Rescue: no disaster but down to earth. Clin Neuroradiol 2013; 23: 1-3

34 Berkhemer OA, Fransen PSS, Beumer D et al. A randomized trial of intraarterial treatment for acute ischemic stroke. N Engl J Med 2015; 372: $11-20$

35 Goyal M, Demchuk AM, Menon BK et al. Randomized Assessment of Rapid Endovascular Treatment of Ischemic Stroke. N Engl J Med 2015, 150211090353006

36 Campbell BCV, Mitchell PJ, Kleinig TJ et al. Endovascular Therapy for Ischemic Stroke with Perfusion-Imaging Selection. N Engl J Med 2015, 150211090353006

37 Saver JL, Goyal M, Bonafe A et al. Stent-Retriever Thrombectomy after Intravenous t-PA vs. t-PA Alone in Stroke. N Engl J Med 2015, 150417023017004

38 Jovin TG, Chamorro A, Cobo E et al. Thrombectomy within 8 Hours after Symptom Onset in Ischemic Stroke. N Engl J Med 2015, 150417035025009

39 Sardar P, Chatterjee S, Giri $J$ et al. Endovascular therapy for acute ischaemic stroke: a systematic review and meta-analysis of randomized trials. Eur Heart J 2015; 36: $2373-2380$

40 Consensus statement on mechanical thrombectomy in acute ischemic stroke - ESO-Karolinska Stroke Update 2014 in collaboration with ESMINT and ESNR. http://www.Strokeupdate.org/consensus-StatementMechanical-Thrombectomy-Acute-Ischemic-Stroke

41 Powers WJ, Derdeyn CP, Biller J et al. 2015 AHA/ASA Focused Update of the 2013 Guidelines for the Early Management of Patients With Acute Ischemic Stroke Regarding Endovascular Treatment: A Guideline for Healthcare Professionals From the American Heart Association/American Stroke Association. Stroke 2015; 46: 3020-3035

42 Navia P, Larrea JA, Pardo E et al. Initial experience using the 3MAX cerebral reperfusion catheter in the endovascular treatment of acute ischemic stroke of distal arteries. J Neurointerv Surg 2015, neurintsurg-2015-011798 
43 Dorn F, Lockau H, Stetefeld H et al. Mechanical Thrombectomy of M2Occlusion. J Stroke Cerebrovasc Dis 2015; 24: 1465-1470

44 Porelli S, Leonardi $M$, Stafa $A$ et al. CT angiography in an acute stroke protocol: correlation between occlusion site and outcome of intravenous thrombolysis. Interv Neuroradiol 2013; 19: 87-96
45 Friedrich B, Gawlitza M, Schob S et al. Distance to thrombus in acute middle cerebral artery occlusion: a predictor of outcome after intravenous thrombolysis for acute ischemic stroke. Stroke 2015; 46: 692 - 696

46 van der Hoeven EJRJ, Schonewille WJ, Vos JA et al. The Basilar Artery International Cooperation Study (BASICS): study protocol for a randomised controlled trial. Trials 2013; 14: 200 